\title{
Neurons Are a Primary Driver of Inflammation via Release of HMGB1
}

\author{
Huan Yang ${ }^{1, *}$, Ulf Andersson ${ }^{2, *(D)}$ and Michael Brines ${ }^{1}$ (D) \\ 1 Institute for Bioelectronic Medicine, The Feinstein Institutes for Medical Research, 350 Community Drive, \\ Manhasset, NY 11030, USA; brinesmichael@gmail.com \\ 2 Department of Women's and Children's Health, Karolinska Institute, Karolinska University Hospital, \\ 17176 Stockholm, Sweden \\ * Correspondence: hyang@northwell.edu (H.Y.); ulf.andersson@ki.se (U.A.)
}

check for updates

Citation: Yang, H.; Andersson, U.; Brines, M. Neurons Are a Primary Driver of Inflammation via Release of HMGB1. Cells 2021, 10, 2791.

https://doi.org/10.3390/cells10102791

Academic Editors: Shih-Heng

(David) Chen and

Atsufumi Kawabata

Received: 3 September 2021

Accepted: 14 October 2021

Published: 18 October 2021

Publisher's Note: MDPI stays neutral with regard to jurisdictional claims in published maps and institutional affiliations.

Copyright: (C) 2021 by the authors. Licensee MDPI, Basel, Switzerland. This article is an open access article distributed under the terms and conditions of the Creative Commons Attribution (CC BY) license (https:/ / creativecommons.org/licenses/by/ $4.0 /)$.

\begin{abstract}
Recent data show that activation of nociceptive (sensory) nerves turns on localized inflammation within the innervated area in a retrograde manner (antidromically), even in the absence of tissue injury or molecular markers of foreign invaders. This neuroinflammatory process is activated and sustained by the release of neuronal products, such as neuropeptides, with the subsequent amplification via recruitment of immunocompetent cells, including macrophages and lymphocytes. High mobility group box 1 protein (HMGB1) is a highly conserved, well characterized damageassociated molecular pattern molecule expressed by many cells, including nociceptors and is a marker of inflammatory diseases. In this review, we summarize recent evidence showing that neuronal HMGB1 is required for the development of neuroinflammation, as knock out limited to neurons or its neutralization via antibodies ameliorate injury in models of nerve injury and of arthritis. Further, the results of study show that HMGB1 is actively released during neuronal depolarization and thus plays a previously unrecognized key etiologic role in the initiation and amplification of neuroinflammation. Direct targeting of HMGB1 is a promising approach for novel anti-inflammatory therapy.
\end{abstract}

Keywords: high mobility group box 1; TRPV1; nociception; cytokine; inflammation; nerve injury; arthritis

\section{Introduction: Activation of Nociceptive Neurons Turns on Inflammation}

Recent studies have shown that activation of nociceptors (TRPV1+) in the absence of tissue damage or pathogen-related products fully mobilizes local innate immune responses. For example, using optogenetic techniques, Cohen et al. have reported that sterile triggering of cutaneous nociceptors produces a sustained multicellular immune response within the innervated tissue via the antidromic nerve reflex arc [1]. To underscore the critical role of neurons in the process, this biological response has been termed neuroinflammation. Many different processes which stimulate sensory neurons can also simultaneously activate inflammatory processes and result in acute and chronic diseases. As one example, immuneantibody complexes of cartilage collagen within the joint space activate sensory neurons via Fc receptors for IgG resulting in pain behavior before the development of inflammation and damage within the joint [2]. Interfering with neuronal activation greatly attenuates subsequent joint inflammation, underscoring the importance of neuroinflammation in the pathophysiology [3]. Notably, clinical experience also supports a critical role for sensory nerves in the development of inflammatory diseases. As one example, Kane et al. have reported that a patient with psoriatic arthritis who had suffered nerve transection of the fourth finger prior to contracting the disease, was completely protected from the development of inflammation and joint deformity in that digit in contrast to the other fingers (Figure 1) [4]. Furthermore, an experimental arthritis study designed to investigate a possible relationship between joint innervation and joint inflammation demonstrated that prior sensory denervation, with preserved motor function, prevented the development of 
arthritis in the denervated knee [4]. Importantly, persistent activation or malfunction of the nociceptive system also gives rise to chronic pain [5]. As reviewed by Peirs and Seal, noxious stimuli activate primary sensory neurons that transmit nociceptive information to the spinal and medullary dorsal horns. A cascade of signaling subsequently leads to neuroinflammation and perceived pain [6].

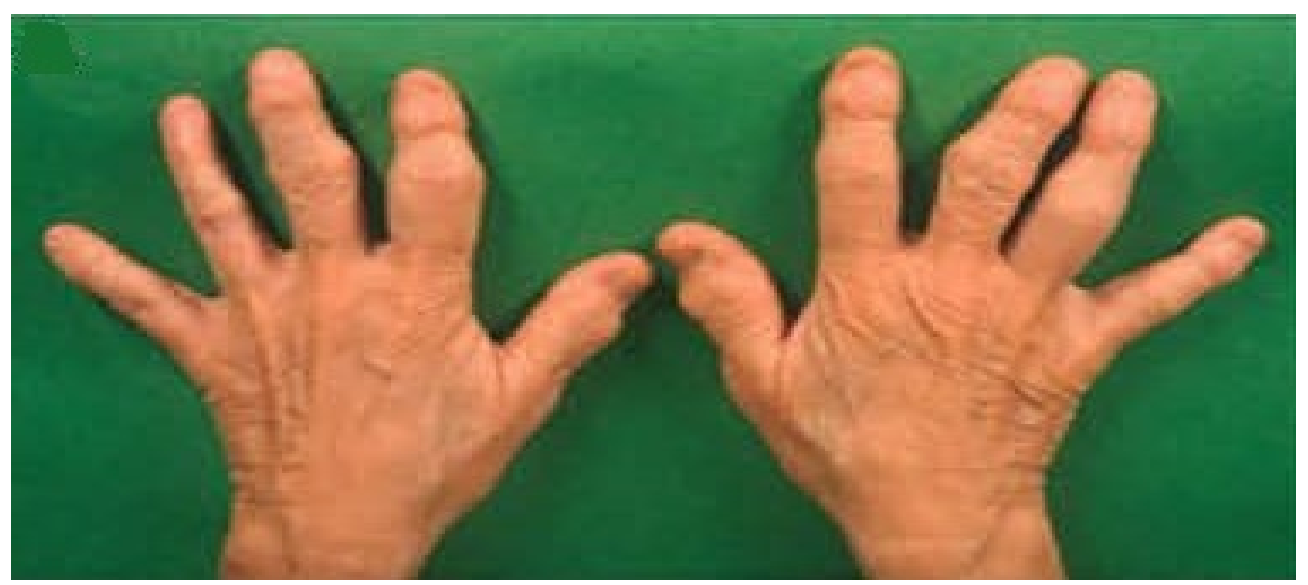

Figure 1. Digital nerve loss protects against arthritis-induced joint destruction. Swelling and joint deformity exist for distal and proximal interphalangeal joints except for the fourth digit in a patient suffering from long-standing psoriatic arthritis. She had previously suffered a complete traumatic transection of the fourth digital nerve as a child, before the onset of arthritis, which had resulted in sensory denervation (Reproduced from Kane et al. [4]).

The current paradigm of the pathophysiology of neuroinflammation has focused on the observation that stimulated sensory neurons actively release a variety of vasoactive and immune stimulating molecules, typically histamine and neuropeptides [7]. These mediators act synergistically with local immunocompetent cells, e.g., Langerhans cells, to establish a mature inflammatory complex ultimately culminating in the accumulation of neutrophils and lymphocytes, generally associated with secondary tissue damage and maintenance of a state of disease. However, neurons also actively restrict the local inflammatory response via monitoring by the vagus nerve and the central nervous system. Based on this information, the central nervous system exerts homeostatic controls via the autonomic nervous system and the hypothalamic-pituitary-adrenal system [8].

\section{Role of High Mobility Group Box 1 Protein (HMGB1) in the Inflammatory Response}

In addition to the molecular products well-known for release from sensory neurons, other important molecules have been implicated in the immune response. One key player in activating inflammation is HMGB1, which is an evolutionarily highly conserved, nuclear, non-histone DNA binding protein present in all nucleated cells [9]. Prior work has shown that HMGB1 is passively released during lytic cell death processes, as well as secreted by activated innate immune cells. Certain post-translationally modified isoforms of HMGB1 operate extracellularly as proinflammatory mediators in infectious and sterile inflammatory conditions [10-12]. Further, HMGB1 levels in the central nervous system and in dorsal root ganglion (DRG) cells are elevated in many neuronal injury models including tibial nerve injury [13], stress-induced headache [14], ischemic brain damage [15], cocaine exposure [16], ethanol overdose [17], morphine-mediated analgesic tolerance and hyperalgesia [18], and subarachnoid hemorrhage [19]. Stressed and damaged neurons collaborate with activated microglial cells and astrocytes to further propagate inflammation via proinflammatory molecules including HMGB1. However, important questions regarding the functional role of neuronal HMGB1 in the cellular collaboration driving inflammation in the central nervous system or in the periphery have, until lately, remained elusive. One important, incompletely investigated area is assessing the importance of neuronal HMGB1 in inflam- 
mation and whether its release occurs only via neuronal injury, or whether, similar to immune cells, uninjured neurons can directly release HMGB1 to initiate immune responses. Here, we focus on reviewing recent findings addressing these issues.

\section{HMGB1 Is Actively Released by Nociceptive Neurons}

Nuclear HMGB1 is ubiquitously expressed in the central nervous system including neurons, satellite cells, Schwann cells, microglia, and astrocytes, and the intracellular levels are further enhanced during traumatic neuropathy, denoting a possible link between HMGB1 release and nociception [20]. A programmed nuclear-cytoplasmic translocation of HMGB1 is a prerequisite in innate immune cells for active HMGB1 release via exocytosis of cytoplasmic vesicles such as secretory lysosomes [21] or via exosomal release during sepsis [22]. Studies by Merianda et al. provided direct evidence that, in mice with sciatic nerve injury, HMGB1 located within DRGs shifts from cell bodies towards release [23]. These investigators used L4-L5 DRG neurons cultured from animals that had been conditioned $7 \mathrm{~d}$ previously by unilateral sciatic nerve crush. HMGB1 protein shifts from being cell body-predominant in the naive neurons to being axon-predominant in the injury-conditioned neurons. Immunofluorescent images of cultured neurons showed higher cell body signals in naive neurons and higher axonal signals in injury-conditioned neurons. Hence, this study provided direct evidence that during injury, neuronal HMGB1 shifts from cell bodies to axons towards release. All these findings implicate that HMGB1 is actively released from neurons to elicit extracellular events.

Although neurons do not contain secretory lysosomes, studies have implicated that HMGB1 is actively released from excessively (hyper) depolarized neurons in response to optogenetic stimulation [24], from neurons stimulated by TNF [25] or following ethanol exposure [26]. Using an optogenetic approach, we directly demonstrated that stimulated sensory neurons actively release HMGB1 [27]. Specifically, to selectively activate sensory neurons, we generated transgenic Vglut2-Cre/ChR2-eYFP mice which express channelrhodopsin-2 (ChR2) coupled to an enhanced yellow fluorescent protein (ChR2eYFP) directed by vesicular glutamate transporter type 2 (VGlut2) promoter. ChR2 is a light-gated ion channel that is activated by exposure to blue light. Previous work has shown that activation of these light-gated channels depolarizes the DRG neurons and elicits propagated action potentials [28]. Vesicular glutamate transporter 2 (VGlut2) is expressed by peripheral glutamatergic sensory neurons. Sensory neurons, harvested from dorsal root ganglia of Vglut2-Cre/ChR2-eYFP mice, were then cultured and stimulated by $470 \mathrm{~nm}$ blue light in vitro and subsequently expressed significant levels of cytoplasmic HMGB1 in contrast to unstimulated DRGs. We subsequently observed (Figure 2A) a time-dependent increase in the extracellular HMGB1 concentrations after the optogenetic stimulation [27]. In contrast, photo-stimulation of DRG sensory neurons using yellow light (595 nm), which does not activate ChR2, failed to induce HMGB1 release. These combined results thus indicate that stimulated nociceptors actively translocate nuclear HMGB1 to the cytoplasm for ultimate release at the nerve ending. Lactate dehydrogenase (LDH), a soluble cytoplasmic enzyme released upon cell membrane disruption, was not released during light exposure, further confirming that HMGB1 is actively secreted by stimulated nociceptors, and not passively released via lytic cell death [27] (Figure 2B). In summary, although the full temporal profile of HMGB1 release in response to neuronal activation remains to be determined in future experiments, the results of these studies definitively show that, as with immune cells, sensory neurons can actively release HMGB1 in response to stimulation. That this release is physiologically relevant is shown using neuronal HMGB1 knock-out and neutralization in preclinical models, as discussed below. 
A

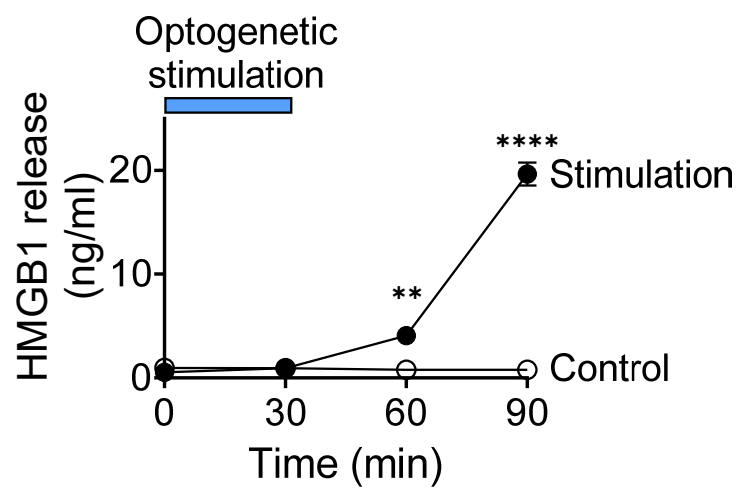

B

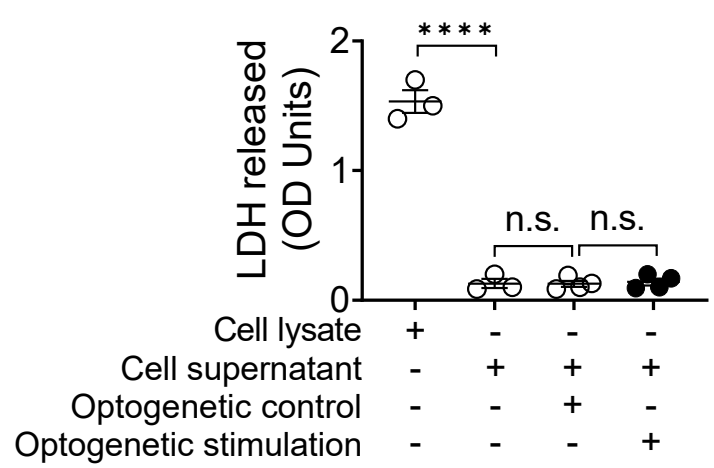

Figure 2. Stimulated neurons actively release HMGB1. (A). Sensory neurons harvested from dorsal root ganglia (DRG) of Vglut2-Cre/ChR2-eYFP mice were cultured and exposed to (470 nm; stimulates) or yellow light (595 nm, not-stimulating control) at $20 \mathrm{~Hz}$, and 10\% duty cycle for $30 \mathrm{~min}$ using optical fiber-coupled LEDs. Blue bar indicates the duration of stimulation. A time-dependent increase in secreted HMGB1 levels is observed following optogenetic stimulation (at 60 min: ${ }^{* *}: p<0.01$, at 90 min: $\left.{ }^{* * * *}: p<0.0001\right)$; reproduced from Yang et al. [27]. (B). DRG viability was assessed by release of the soluble cytoplasmic enzyme lactate dehydrogenase (LDH), which leaks out following membrane disruption. Cell lysate was included as positive control. No significant increase in cell death is observed following optogenetic stimulation. $n=3-4$ separate experiments, and each performed in duplicate $(* * * *: p<0.0001)$, n.s.: not significant; reproduced from Yang et al. [27].

\section{HMGB1 Induces Nociceptive Responses via Neuronal TLR4-Dependent Mechanisms}

The biological activities of HMGB1 depend upon receptor binding which is sensitive to the redox state of each of HMGB1's three cysteines [11]. Fully reduced (all-thiol) HMGB1 exerts chemotactic activity by forming a heterocomplex with the chemokines CXCL12 and CXCR4, which initiates recruitment of inflammatory cells in a synergistic fashion, compared to CXCL12 alone [29,30]. In contrast, the cytokine-stimulating activity of HMGB1 requires cysteine 23 and 45 to form a disulfide link as a result by mild oxidation, while keeping the C106 residue in its reduced state [31]. This disulfide isoform exclusively binds and activates the TLR4/MD-2 complex [32,33]. Finally, HMGB1 with any of the cysteines terminally oxidized (sulfonyl HMGB1) has until recently been regarded as an immunologically inactive molecule. However, recent studies indicate that sulfonyl HMGB1 is actually a potent anti-inflammatory molecule [34].

The HMGB1 molecule has binding sites for both the receptor for advanced glycation end-product (RAGE) and Toll-like receptor 4 (TLR4; Figure 3A). Using global TLR4 knockout (KO) mice, Svensson et al. demonstrated that TLR4 is required for HMGB1mediated hyperalgesia $[35,36]$. However, no previous study has investigated the impact of tissue-specific TLR4 in neuronal HMGB1 signaling. To gain insight into the mechanism of neuronal HMGB1-induced nociceptive responses, we generated novel neuronal TLR4 $\left(\right.$ Syn-Cre/TLR4 ${ }^{\mathrm{fl} / \mathrm{fl}}$ ) and RAGE-specific KO (Syn-Cre/RAGE ${ }^{\mathrm{fl} / \mathrm{fl}}$ ) mouse models. To determine if the absence of neuronal TLR4 is sufficient to significantly reduce hyperalgesia in the presence of high levels of HMGB1, mice had paw injections of disulfide HMGB1 $(6 \mu \mathrm{g} / \mathrm{paw})$ and mechanical hypersensitivity was assessed $5 \mathrm{~h}$ afterwards. Similar to global $\mathrm{KO}$, neuronal specific TLR4 KO had significant protection against HMGB1-induced allodynia as compared to wild type or neuronal RAGE KO mice (Figure 3B). In agreement with this observation, mice subjected to sciatic nerve injury developed hypersensitivity in wild type and neuronal RAGE KO as compared to sham-operated controls. In contrast, neuronal TLR4 KO mice were significantly protected from this sciatic injury-induced allodynia (Figure 3C). Taken together, these findings show that HMGB1-inducing nociceptive responses predominantly occur via a neuronal TLR4-dependent signaling mechanism. The effect of neuronal knock-out of HMGB1 on TLR4 expression, if any, is currently unknown. 
A

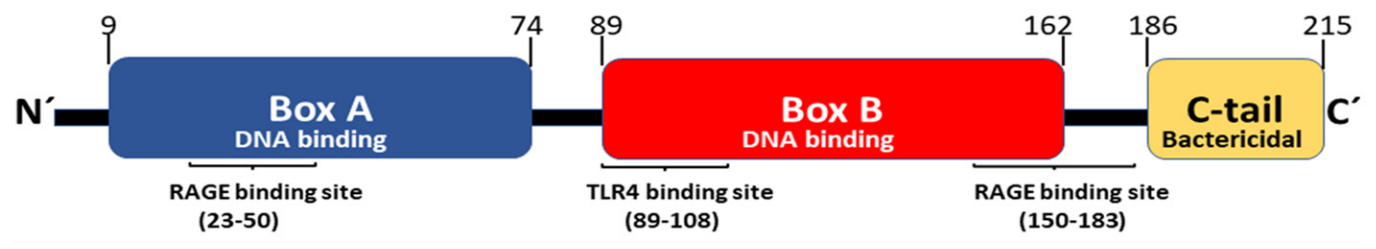

B

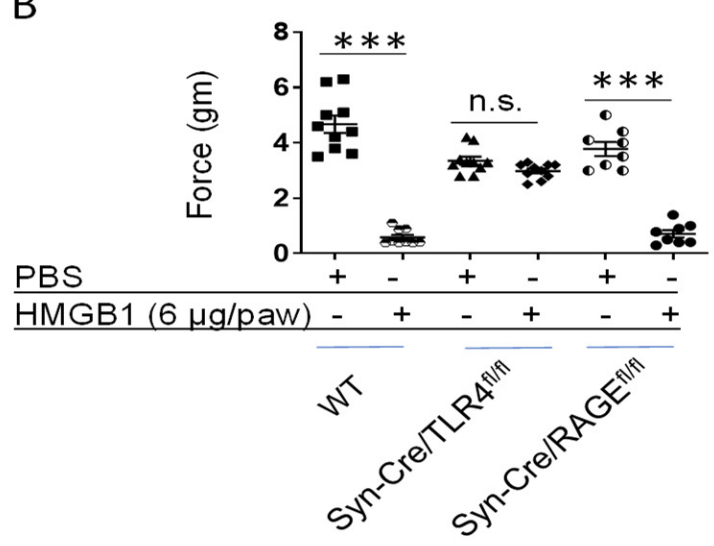

C

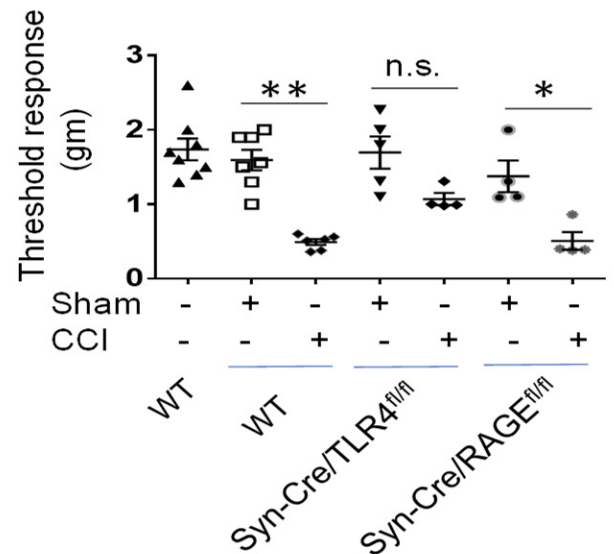

Figure 3. Neuronal TLR4, not RAGE, mediates HMGB1-induced nociceptive response. (A). Location of receptor binding sites in the HMGB1 molecule. The human HMGB1 protein expresses 214 amino acid residues and contains three functional domains: two DNA binding regions termed Box A and Box B, and a bactericidal C-terminal tail. The three ligand binding sites of the HMGB1 protein: RAGE binding site (23-50 aa'), TLR4 binding site (89-108 aa') [31] and RAGE binding site (150-183 aa'). (B). Wild type (C57BL/6), Syn-Cre/TLR4 ${ }^{\mathrm{fl} / \mathrm{fl}}$ and Syn-Cre/RAGE ${ }^{\mathrm{fl} / \mathrm{fl}}$ mice (generated by crossing Rage

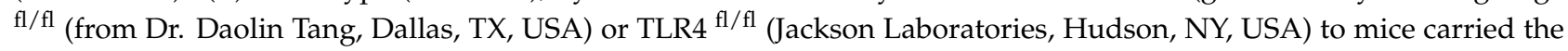
Synapsin I promoter-driven Cre recombinanse transgene (Jackson Laboratories)) had intra-plantar injection of HMGB1 $(6 \mu \mathrm{g} / \mathrm{paw})$ or vehicle (PBS) on hindpaw, and $5 \mathrm{~h}$ later mechanical hypersensitivity (dynamic plantar aesthesiometer) was assessed. ( $n=8-10$ mice per group. $\left.{ }^{* * *}: p<0.0001\right)$. n.s.: not significant. (C). Wild type (WT), Syn-Cre/TLR4 ${ }^{\mathrm{fl} / \mathrm{fl}}$ and Syn-Cre/RAGE ${ }^{\mathrm{fl} / \mathrm{fl}}$ mice (male, $8-12$ weeks old) were subjected to sciatic nerve ligation surgery (CCI) or sham surgery. Two weeks after sciatic nerve ligation (or sham) surgery, mechanical hypersensitivity (von Frey filament) was assessed. $n=4-8$ per group. ${ }^{*}: p<0.02 .{ }^{*}: p<0.001$. n.s.: not significant.

\section{Neuronal HMGB1 Ablation/Neutralization Reduces Inflammation and Hyperalgesia}

The functional in vivo role of nociceptors and HMGB1 in inflammation was recently evaluated in studies of mice with HMGB1 expression silenced only in neurons [27]. Using mice expressing Cre recombinase under the control of neuronal-specific synapsin promoter, and by crossing synapsin-Cre (Syn-Cre) mice with floxed HMGB1 mice (HMGB1 $1^{\mathrm{fl} / \mathrm{fl}}$ ), we have generated mice with neuronal-specific ablation of HMGB1 (Syn-Cre/HMGB1 ${ }^{\mathrm{fl} / \mathrm{fl}}$ ). This strain of mice allows us to determine the effects of selective neuronal HMGB1 deficiency in neuroinflammation. Standardized sciatic nerve injury which generates severe neurogenic inflammation in wild type mice had a much milder course of cutaneous paw inflammation and allodynia in the neuronal-specific HMGB1 knock out (Syn-Cre/HMGB1 ${ }^{\mathrm{fl} / \mathrm{fl}}$ ) animals (Figure 4A). Further, experimental collagen antibody-induced arthritis (CAIA) in wildtype mice induces painful, destructive polyarthritis that depends on nociceptor-induced neuroinflammation $[37,38]$. The onset of CAIA in HMGB1 lacking Syn-Cre/HMGB1 ${ }^{\mathrm{fl} / \mathrm{fl}}$ mice was significantly delayed compared to that in controls and the neuronal HMGB1 knockout mice were subsequently substantially protected from joint inflammation and allodynia (Figure 4B). Thus, nociceptor HMGB1 is an essential mediator of the neuroinflammatory response to different forms of tissue injury. 
A

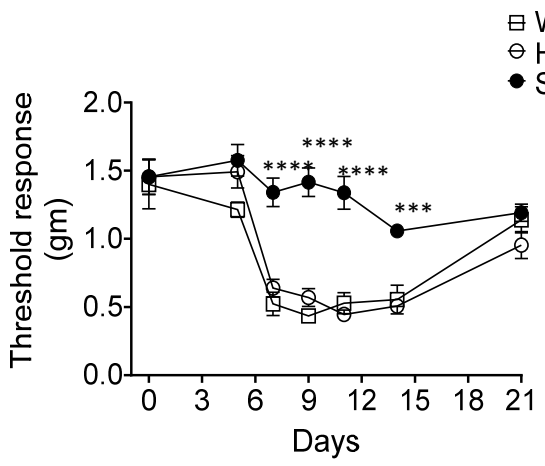

$\boxminus$ WT

$\ominus$ HMGB1 ${ }^{\mathrm{fl} / \mathrm{fl}}$

- Syn-Cre/HMGB1 $1^{\mathrm{f} / \mathrm{fl}}$

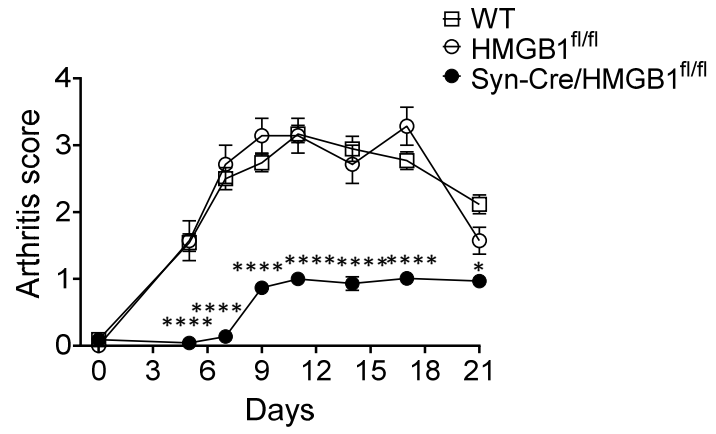

Figure 4. Ablation of neuronal HMGB1 reduces joint inflammation and cartilage destruction, while improving hyperalgesia in murine collagen antibody-induced arthritis. Polyarthritis was induced by administration of anti-collagen antibodies in mice. Wild type (WT) and HMGB1 ${ }^{\mathrm{fl} / \mathrm{fl}}$ control mice develop increased mechanical hypersensitivity (A) and polyarthritis (B). A significantly delayed onset and reduced severity of polyarthritis are observed in HMGB1 knock out (Syn-Cre/HMGB1 ${ }^{\mathrm{fl} / \mathrm{fl}}$ ) mice. This is accompanied by a marked reduction in mechanical hyperalgesia. (Syn-Cre/HMGB1 ${ }^{\mathrm{fl} / \mathrm{fl}}$ versus $\mathrm{HMGB} 1^{\mathrm{fl} / \mathrm{fl}}$ group: ${ }^{*} p<0.05,{ }^{* *} p<0.001,{ }^{* * *} p<0.0001$. Reproduced from Yang et al. [27]).

HMGB1-specific monoclonal antibodies have been demonstrated to be effective for the treatment of a wide range of neuroinflammatory diseases in multiple preclinical models, including stroke [39-42], traumatic brain injury [43], Parkinson's disease [44], epilepsy [45,46], autoimmune encephalomyelitis [47,48], Alzheimer's disease [24], nerve root compression [49], and cognitive decline after sepsis or major surgery [50,51]. Potential therapeutic implications have been addressed in the comprehensive recent reviews of Paudel et al. [52] and Nishibori et al. [53,54].

Interestingly, the therapeutic results seem to be more consistent and successful in disease models where neuronal HMGB1 is involved than in non-neuronal HMGB1-dependent inflammatory conditions. The reasons for these discrepant therapeutic outcomes are presently not fully understood, but may depend upon the molecular form of HMGB1. Specifically, extracellular HMGB1 either generates inflammation by operating as an individual molecule that signals via TLR4 or the receptor for advanced glycated end products (RAGE) or, alternatively, by acting complex-bound to extracellular DAMP/PAMP molecules. These complexes are endocytosed via RAGE expressed on macrophages and other innate immunity cells and end up in the endolysosomal system of these cells. There, during acidic conditions, HMGB1 acts as a detergent and damages the lysosomal membrane allowing partner molecules access to cytosolic sensors including inflammasomes that initiate inflammation [55]. Extracellular HMGB1 has a vigorous capacity to form these complexes with partner molecules during systemic inflammatory conditions. From a therapeutic point of view, this biology may create major obstacles for HMGB1-specific antagonists to recognize and neutralize HMGB1. However, the neuronally released HMGB1 can be discharged close to its cognate TLR4 receptors with much less risk that HMGB1 will first bind to other molecules, causing steric hindrance for HMGB1-specific antagonists to mediate beneficial therapeutic effects. We thus speculate that future treatment with HMGB1-specific antagonists might offer a unique clinical opportunity to pacify HMGB1 in diseases where harmful neuronal HMGB1 release is at hand. Many scientists and clinicians interested in HMGB1 are puzzled and disappointed by the fact that, after more than two decades of HMGB1 research, we still lack successful therapeutic HMGB1 antagonists in clinical use. If our speculations about problems and opportunities for HMGB1-specific antibody treatment are correct, they might be helpful to optimize future clinical therapeutic strategies.

\section{Perspective}

Studies of nociception and neuropathic pain have revealed that HMGB1 release from injured or activated cells occurs as it translocates from the nucleus to the cytosol as a mech- 
anism of active release [35,56-58]. However, it was not previously known whether HMGB1 is actively released by neurons during neuropathic inflammatory pain syndromes. Our critical recent findings not only confirmed the role of actively released HMGB1, but also established that neuronal HMGB1 is required to induce neuroinflammation in tissues [27]. The active involvement of neurons in the initiation of inflammation and tissue damage is direct evidence that the nervous system can stimulate innate immune responses and inflammation. It has been long established that neurotransmission in the vagus nerve inhibits inflammation and nociceptive responses through "the inflammatory reflex" [59,60]. Successful preclinical as well as clinical studies with implanted or external vagus nerve stimulators in patients with rheumatoid arthritis or inflammatory bowel disease have validated the importance of this mechanism [61-66]. The new observation that neurons directly release HMGB1 as the trigger of immune system defense during tissue injury, while simultaneously directing anti-inflammatory activities via the inflammatory reflex, establishes an important framework to understand how the nervous system evolved to reflexively enhance or inhibit inflammation. The ability to inhibit and stimulate inflammation yields a highly controllable homeostatic process to modulate inflammation to optimize survival and propagation of the species against threat from infection and injury (Figure 5). This new understanding of the neural reflex basis of immune homeostasis, and revelation of underlying mechanisms for the neural control of inflammatory signaling, paves the way for the development of experimental therapeutics, e.g., specific HMGB1 antagonists, or of electromagnetic devices to block neuronal HMGB1 release as novel treatments for inflammatory diseases.

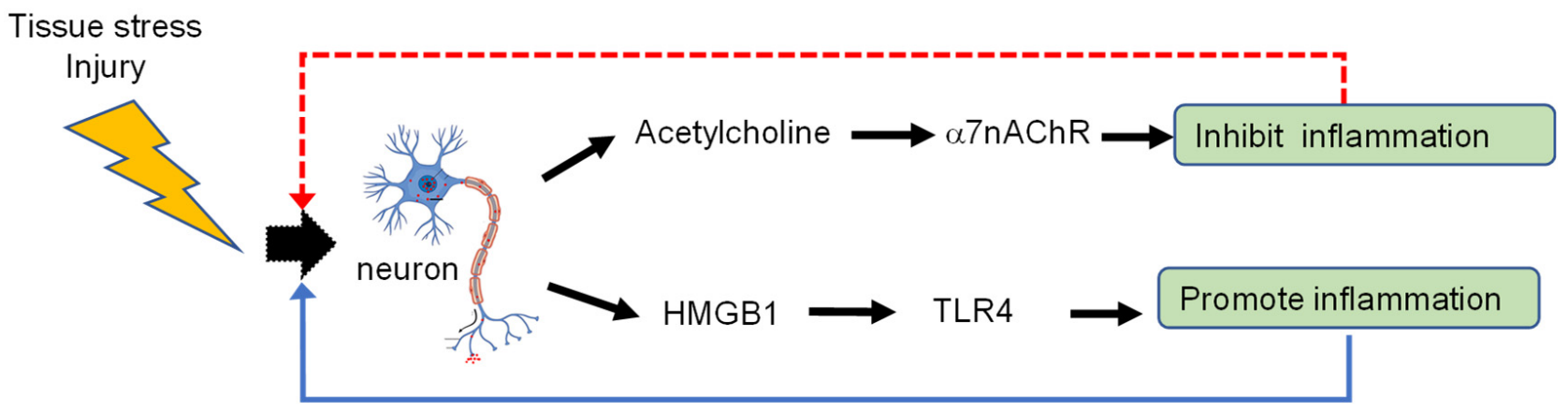

Figure 5. Neurons regulate the inflammatory milieu. Neurons both activate inflammation via release of HMGB1 and other pro-inflammatory molecules, as well as inhibit inflammation via acetylcholine release from vagal nerve fibers (the inflammatory reflex) [60]. However, these actions also feedback upon neurons to provide inhibition (red dashed line) to counter-balance further amplification (blue solid line) of inflammation. The discovery that neuronal HMGB1, a well characterized endogenous pro-inflammatory mediator, is a fundamental driver of the cascade of immune system defense provides a mechanism by which the nervous system provides yin-yang control of anti- and pro-inflammatory factors to maintain homeostasis.

Author Contributions: H.Y., U.A. and M.B. wrote the draft manuscript and designed figures. All authors contributed to the elaboration of the manuscript. All authors have read and agreed to the published version of the manuscript.

Funding: This research received no external funding.

Conflicts of Interest: The authors declare no conflict of interest.

\section{Abbreviations}

CAIA: collagen antibody-induced arthritis; CCI: chronic constriction injury; CNS: central nervous system; HMGB1: high mobility group box 1; RAGE: receptor for advanced glycation endproduct; TLR4: Toll-like receptor 4; and TRPV1: transient receptor potential vanilloid type 1. 


\section{References}

1. Cohen, J.A.; Edwards, T.N.; Liu, A.W.; Hirai, T.; Jones, M.R.; Wu, J.; Li, Y.; Zhang, S.; Ho, J.; Davis, B.M.; et al. Cutaneous TRPV1(+) Neurons Trigger Protective Innate Type 17 Anticipatory Immunity. Cell 2019, 178, 919-932.e914. [CrossRef]

2. Bersellini Farinotti, A.; Wigerblad, G.; Nascimento, D.; Bas, D.B.; Morado Urbina, C.; Nandakumar, K.S.; Sandor, K.; Xu, B.; Abdelmoaty, S.; Hunt, M.A.; et al. Cartilage-binding antibodies induce pain through immune complex-mediated activation of neurons. J. Exp. Med. 2019, 216, 1904-1924. [CrossRef]

3. Borbély, É.; Kiss, T.; Szabadfi, K.; Pintér, E.; Szolcsányi, J.; Helyes, Z.; Botz, B. Complex Role of Capsaicin-Sensitive Afferents in the Collagen Antibody-Induced Autoimmune Arthritis of the Mouse. Sci. Rep. 2018, 8, 15916. [CrossRef]

4. Kane, D.; Lockhart, J.C.; Balint, P.V.; Mann, C.; Ferrell, W.R.; McInnes, I.B. Protective effect of sensory denervation in inflammatory arthritis (evidence of regulatory neuroimmune pathways in the arthritic joint). Ann. Rheum. Dis. 2005, 64, 325-327. [CrossRef]

5. Grace, P.M.; Tawfik, V.L.; Svensson, C.I.; Burton, M.D.; Loggia, M.L.; Hutchinson, M.R. The Neuroimmunology of Chronic Pain: From Rodents to Humans. J. Neurosci. Off. J. Soc. Neurosci. 2021, 41, 855-865. [CrossRef]

6. Peirs, C.; Seal, R.P. Neural circuits for pain: Recent advances and current views. Science 2016, 354, 578-584. [CrossRef]

7. Abdulkhaleq, L.A.; Assi, M.A.; Abdullah, R.; Zamri-Saad, M.; Taufiq-Yap, Y.H.; Hezmee, M.N.M. The crucial roles of inflammatory mediators in inflammation: A review. Vet. World 2018, 11, 627-635. [CrossRef]

8. Smith, S.M.; Vale, W.W. The role of the hypothalamic-pituitary-adrenal axis in neuroendocrine responses to stress. Dialogues Clin. Neurosci. 2006, 8, 383-395. [CrossRef]

9. Kang, R.; Chen, R.; Zhang, Q.; Hou, W.; Wu, S.; Cao, L.; Huang, J.; Yu, Y.; Fan, X.G.; Yan, Z.; et al. HMGB1 in health and disease. Mol. Asp. Med. 2014, 40,1-116. [CrossRef]

10. Andersson, U.; Tracey, K.J. HMGB1 is a therapeutic target for sterile inflammation and infection. Annu. Rev. Immunol. 2011, 29, 139-162. [CrossRef]

11. Yang, H.; Wang, H.; Andersson, U. Targeting Inflammation Driven by HMGB1. Front. Immunol. 2020, 11, 484. [CrossRef]

12. Andersson, U.; Yang, H.; Harris, H. Extracellular HMGB1 as a therapeutic target in inflammatory diseases. Expert Opin. Ther. Targets 2018, 22, 263-277. [CrossRef]

13. Feldman, P.; Due, M.R.; Ripsch, M.S.; Khanna, R.; White, F.A. The persistent release of HMGB1 contributes to tactile hyperalgesia in a rodent model of neuropathic pain. J. Neuroinflamm. 2012, 9, 180. [CrossRef]

14. Karatas, H.; Erdener, S.E.; Gursoy-Ozdemir, Y.; Lule, S.; Eren-Koçak, E.; Sen, Z.D.; Dalkara, T. Spreading depression triggers headache by activating neuronal Panx1 channels. Science 2013, 339, 1092-1095. [CrossRef]

15. Faraco, G.; Fossati, S.; Bianchi, M.E.; Patrone, M.; Pedrazzi, M.; Sparatore, B.; Moroni, F.; Chiarugi, A. High mobility group box 1 protein is released by neural cells upon different stresses and worsens ischemic neurodegeneration in vitro and in vivo. $J$. Neurochem. 2007, 103, 590-603. [CrossRef]

16. Gao, S.Q.; Zhang, H.; He, J.G.; Zheng, H.L.; Zhang, P.W.; Xu, J.F.; Shen, Z.C.; Zhao, H.H.; Wang, F.; Hu, Z.L.; et al. Neuronal HMGB1 in nucleus accumbens regulates cocaine reward memory. Addict. Biol. 2019, 25, e12739. [CrossRef]

17. Wang, X.; Chu, G.; Yang, Z.; Sun, Y.; Zhou, H.; Li, M.; Shi, J.; Tian, B.; Zhang, C.; Meng, X. Ethanol directly induced HMGB1 release through NOX2/NLRP1 inflammasome in neuronal cells. Toxicology 2015, 334, 104-110. [CrossRef]

18. Qian, J.; Zhu, Y.; Bai, L.; Gao, Y.; Jiang, M.; Xing, F.; Zhang, J.; Zhao, W.; Gu, H.; Mi, Y.; et al. Chronic morphine-mediated upregulation of high mobility group box 1 in the spinal cord contributes to analgesic tolerance and hyperalgesia in rats. Neurotherapeutics 2019, 17, 722-742. [CrossRef]

19. Sun, Q.; Wu, W.; Hu, Y.C.; Li, H.; Zhang, D.; Li, S.; Li, W.; Li, W.D.; Ma, B.; Zhu, J.H.; et al. Early release of high-mobility group box 1 (HMGB1) from neurons in experimental subarachnoid hemorrhage in vivo and in vitro. J. Neuroinflamm. 2014, 11, 106. [CrossRef]

20. Wan, W.; Cao, L.; Khanabdali, R.; Kalionis, B.; Tai, X.; Xia, S. The Emerging Role of HMGB1 in Neuropathic Pain: A Potential Therapeutic Target for Neuroinflammation. J. Immunol. Res. 2016, 2016, 6430423. [CrossRef]

21. Gardella, S.; Andrei, C.; Ferrera, D.; Lotti, L.V.; Torrisi, M.R.; Bianchi, M.E.; Rubartelli, A. The nuclear protein HMGB1 is secreted by monocytes via a non-classical, vesicle-mediated secretory pathway. EMBO Rep. 2002, 3, 995-1001. [CrossRef]

22. Yang, K.; Fan, M.; Wang, X.; Xu, J.; Wang, Y.; Tu, F.; Gill, P.S.; Ha, T.; Liu, L.; Williams, D.L.; et al. Lactate promotes macrophage HMGB1 lactylation, acetylation, and exosomal release in polymicrobial sepsis. Cell Death Differ. 2021, 1-14. [CrossRef]

23. Merianda, T.T.; Coleman, J.; Kim, H.H.; Kumar Sahoo, P.; Gomes, C.; Brito-Vargas, P.; Rauvala, H.; Blesch, A.; Yoo, S.; Twiss, J.L. Axonal amphoterin mRNA is regulated by translational control and enhances axon outgrowth. J. Neurosci. Off. J. Soc. Neurosci. 2015, 35, 5693-5706. [CrossRef]

24. Fujita, K.; Motoki, K.; Tagawa, K.; Chen, X.; Hama, H.; Nakajima, K.; Homma, H.; Tamura, T.; Watanabe, H.; Katsuno, M.; et al. HMGB1, a pathogenic molecule that induces neurite degeneration via TLR4-MARCKS, is a potential therapeutic target for Alzheimer's disease. Sci. Rep. 2016, 6, 31895. [CrossRef] [PubMed]

25. Sun, Y.; Chen, H.; Dai, J.; Wan, Z.; Xiong, P.; Xu, Y.; Han, Z.; Chai, W.; Gong, F.; Zheng, F. Glycyrrhizin Protects Mice Against Experimental Autoimmune Encephalomyelitis by Inhibiting High-Mobility Group Box 1 (HMGB1) Expression and Neuronal HMGB1 Release. Front. Immunol. 2018, 9, 1518. [CrossRef] [PubMed]

26. Zou, J.Y.; Crews, F.T. Release of neuronal HMGB1 by ethanol through decreased HDAC activity activates brain neuroimmune signaling. PLoS ONE 2014, 9, e87915. [CrossRef] 
27. Yang, H.; Zeng, Q.; Silverman, H.A.; Gunasekaran, M.; George, S.J.; Devarajan, A.; Addorisio, M.E.; Li, J.; Tsaava, T.; Shah, V.; et al. HMGB1 released from nociceptors mediates inflammation. Proc. Natl. Acad. Sci. USA 2021, 118, e2102034118. [CrossRef] [PubMed]

28. Daou, I.; Tuttle, A.H.; Longo, G.; Wieskopf, J.S.; Bonin, R.P.; Ase, A.R.; Wood, J.N.; De Koninck, Y.; Ribeiro-da-Silva, A.; Mogil, J.S.; et al. Remote optogenetic activation and sensitization of pain pathways in freely moving mice. J. Neurosci. 2013, 33, 18631-18640. [CrossRef] [PubMed]

29. Schiraldi, M.; Raucci, A.; Muñoz, L.M.; Livoti, E.; Celona, B.; Venereau, E.; Apuzzo, T.; De Marchis, F.; Pedotti, M.; Bachi, A.; et al. HMGB1 promotes recruitment of inflammatory cells to damaged tissues by forming a complex with CXCL12 and signaling via CXCR4. J. Exp. Med. 2012, 209, 551-563. [CrossRef] [PubMed]

30. Venereau, E.; Casalgrandi, M.; Schiraldi, M.; Antoine, D.J.; Cattaneo, A.; De Marchis, F.; Liu, J.; Antonelli, A.; Preti, A.; Raeli, L.; et al. Mutually exclusive redox forms of HMGB1 promote cell recruitment or proinflammatory cytokine release. J. Exp. Med. 2012, 209, 1519-1528. [CrossRef]

31. Yang, H.; Hreggvidsdottir, H.S.; Palmblad, K.; Wang, H.; Ochani, M.; Li, J.; Lu, B.; Chavan, S.; Rosas-Ballina, M.; Al-Abed, Y.; et al. A critical cysteine is required for HMGB1 binding to Toll-like receptor 4 and activation of macrophage cytokine release. Proc. Natl. Acad. Sci. USA 2010, 107, 11942-11947. [CrossRef] [PubMed]

32. Yang, H.; Wang, H.; Ju, Z.; Ragab, A.A.; Lundback, P.; Long, W.; Valdes-Ferrer, S.I.; He, M.; Pribis, J.P.; Li, J.; et al. MD-2 is required for disulfide HMGB1-dependent TLR4 signaling. J. Exp. Med. 2015, 212, 5-14. [CrossRef]

33. He, M.; Bianchi, M.E.; Coleman, T.R.; Tracey, K.J.; Al-Abed, Y. Correction to: Exploring the biological functional mechanism of the HMGB1/TLR4/MD-2 complex by surface plasmon resonance. Mol. Med. 2018, 24, 31. [CrossRef] [PubMed]

34. Hubert, P.; Roncarati, P.; Demoulin, S.; Pilard, C.; Ancion, M.; Reynders, C.; Lerho, T.; Bruyere, D.; Lebeau, A.; Radermecker, C.; et al Extracellular HMGB1 blockade inhibits tumor growth through profoundly remodeling immune microenvironment and enhances checkpoint inhibitor-based immunotherapy. J. Immunother. Cancer 2021, 9, e001966. [CrossRef]

35. Agalave, N.M.; Larsson, M.; Abdelmoaty, S.; Su, J.; Baharpoor, A.; Lundback, P.; Palmblad, K.; Andersson, U.; Harris, H.; Svensson, C.I. Spinal HMGB1 induces TLR4-mediated long-lasting hypersensitivity and glial activation and regulates pain-like behavior in experimental arthritis. Pain 2014, 155, 1802-1813. [CrossRef] [PubMed]

36. Agalave, N.M.; Svensson, C.I. Extracellular high-mobility group box 1 protein (HMGB1) as a mediator of persistent pain. Mol. Med. 2015, 20, 569-578. [CrossRef]

37. Su, J.; Gao, T.; Shi, T.; Xiang, Q.; Xu, X.; Wiesenfeld-Hallin, Z.; Hökfelt, T.; Svensson, C.I. Phenotypic changes in dorsal root ganglion and spinal cord in the collagen antibody-induced arthritis mouse model. J. Comp. Neurol. 2015, 523, 1505-1528. [CrossRef] [PubMed]

38. Sakthiswary, R.; Singh, R. Has the median nerve involvement in rheumatoid arthritis been overemphasized? Rev. Bras. Reumatol. 2017, 57, 122-128. [CrossRef]

39. Liu, K.; Mori, S.; Takahashi, H.K.; Tomono, Y.; Wake, H.; Kanke, T.; Sato, Y.; Hiraga, N.; Adachi, N.; Yoshino, T.; et al. Anti-high mobility group box 1 monoclonal antibody ameliorates brain infarction induced by transient ischemia in rats. FASEB J. 2007, 21, 3904-3916. [CrossRef]

40. Zhang, J.; Takahashi, H.K.; Liu, K.; Wake, H.; Liu, R.; Maruo, T.; Date, I.; Yoshino, T.; Ohtsuka, A.; Mori, S.; et al. Anti-high mobility group box-1 monoclonal antibody protects the blood-brain barrier from ischemia-induced disruption in rats. Stroke 2011, 42, 1420-1428. [CrossRef]

41. Wang, D.; Liu, K.; Wake, H.; Teshigawara, K.; Mori, S.; Nishibori, M. Anti-high mobility group box-1 (HMGB1) antibody inhibits hemorrhage-induced brain injury and improved neurological deficits in rats. Sci. Rep. 2017, 7, 46243. [CrossRef]

42. Haruma, J.; Teshigawara, K.; Hishikawa, T.; Wang, D.; Liu, K.; Wake, H.; Mori, S.; Takahashi, H.K.; Sugiu, K.; Date, I.; et al. Anti-high mobility group box-1 (HMGB1) antibody attenuates delayed cerebral vasospasm and brain injury after subarachnoid hemorrhage in rats. Sci. Rep. 2016, 6, 37755. [CrossRef]

43. Okuma, Y.; Liu, K.; Wake, H.; Zhang, J.; Maruo, T.; Date, I.; Yoshino, T.; Ohtsuka, A.; Otani, N.; Tomura, S.; et al. Anti-high mobility group box-1 antibody therapy for traumatic brain injury. Ann. Neurol. 2012, 72, 373-384. [CrossRef]

44. Sasaki, T.; Liu, K.; Agari, T.; Yasuhara, T.; Morimoto, J.; Okazaki, M.; Takeuchi, H.; Toyoshima, A.; Sasada, S.; Shinko, A.; et al. Anti-high mobility group box 1 antibody exerts neuroprotection in a rat model of Parkinson's disease. Exp. Neurol. 2016, 275 Pt 1, 220-231. [CrossRef] [PubMed]

45. Fu, L.; Liu, K.; Wake, H.; Teshigawara, K.; Yoshino, T.; Takahashi, H.; Mori, S.; Nishibori, M. Therapeutic effects of anti-HMGB1 monoclonal antibody on pilocarpine-induced status epilepticus in mice. Sci. Rep. 2017, 7, 1179. [CrossRef] [PubMed]

46. Zhao, J.; Wang, Y.; Xu, C.; Liu, K.; Wang, Y.; Chen, L.; Wu, X.; Gao, F.; Guo, Y.; Zhu, J.; et al. Therapeutic potential of an anti-high mobility group box-1 monoclonal antibody in epilepsy. Brain Behav. Immun. 2017, 64, 308-319. [CrossRef] [PubMed]

47. Uzawa, A.; Mori, M.; Taniguchi, J.; Masuda, S.; Muto, M.; Kuwabara, S. Anti-high mobility group box 1 monoclonal antibody ameliorates experimental autoimmune encephalomyelitis. Clin. Exp. Immunol. 2013, 172, 37-43. [CrossRef] [PubMed]

48. Robinson, A.P.; Caldis, M.W.; Harp, C.T.; Goings, G.E.; Miller, S.D. High-mobility group box 1 protein (HMGB1) neutralization ameliorates experimental autoimmune encephalomyelitis. J. Autoimmun. 2013, 43, 32-43. [CrossRef] [PubMed]

49. Otoshi, K.; Kikuchi, S.; Kato, K.; Sekiguchi, M.; Konno, S. Anti-HMGB1 neutralization antibody improves pain-related behavior induced by application of autologous nucleus pulposus onto nerve roots in rats. Spine 2011, 36, E692-E698. [CrossRef] 
50. Chavan, S.S.; Huerta, P.T.; Robbiati, S.; Valdes-Ferrer, S.I.; Ochani, M.; Dancho, M.; Frankfurt, M.; Volpe, B.T.; Tracey, K.J.; Diamond, B. HMGB1 mediates cognitive impairment in sepsis survivors. Mol. Med. 2012, 18, 930-937. [CrossRef]

51. Terrando, N.; Yang, T.; Wang, X.; Fang, J.; Cao, M.; Andersson, U.; Erlandsson, H.H.; Ouyang, W.; Tong, J. Systemic HMGB1 Neutralization Prevents Postoperative Neurocognitive Dysfunction in Aged Rats. Front. Immunol. 2016, 7, 441. [CrossRef]

52. Paudel, Y.N.; Angelopoulou, E.; Piperi, C.; Othman, I.; Shaikh, M.F. HMGB1-Mediated Neuroinflammatory Responses in Brain Injuries: Potential Mechanisms and Therapeutic Opportunities. Int. J. Mol. Sci. 2020, 21, 4609. [CrossRef] [PubMed]

53. Nishibori, M.; Wang, D.; Ousaka, D.; Wake, H. High Mobility Group Box-1 and Blood-Brain Barrier Disruption. Cells 2020, 9 , 2650. [CrossRef] [PubMed]

54. Nishibori, M.; Mori, S.; Takahashi, H.K. Anti-HMGB1 monoclonal antibody therapy for a wide range of CNS and PNS diseases. J. Pharm. Sci. 2019, 140, 94-101. [CrossRef]

55. Deng, M.; Tang, Y.; Li, W.; Wang, X.; Zhang, R.; Zhang, X.; Zhao, X.; Liu, J.; Tang, C.; Liu, Z.; et al. The Endotoxin Delivery Protein HMGB1 Mediates Caspase-11-Dependent Lethality in Sepsis. Immunity 2018, 49, 740-753. [CrossRef] [PubMed]

56. Nakamura, Y.; Morioka, N.; Abe, H.; Zhang, F.F.; Hisaoka-Nakashima, K.; Liu, K.; Nishibori, M.; Nakata, Y. Neuropathic pain in rats with a partial sciatic nerve ligation is alleviated by intravenous injection of monoclonal antibody to high mobility group box-1. PLoS ONE 2013, 8, e73640. [CrossRef] [PubMed]

57. Matsuura, W.; Harada, S.; Liu, K.; Nishibori, M.; Tokuyama, S. Evidence of a role for spinal HMGB1 in ischemic stress-induced mechanical allodynia in mice. Brain Res. 2018, 1687, 1-10. [CrossRef]

58. Morioka, N.; Miyauchi, K.; Miyashita, K.; Kochi, T.; Zhang, F.F.; Nakamura, Y.; Liu, K.; Wake, H.; Hisaoka-Nakashima, K.; Nishibori, M.; et al. Spinal high-mobility group box-1 induces long-lasting mechanical hypersensitivity through the toll-like receptor 4 and upregulation of interleukin-1beta in activated astrocytes. J. Neurochem. 2019, 150, 738-758. [CrossRef] [PubMed]

59. Tracey, K.J. The inflammatory reflex. Nature 2002, 420, 853-859. [CrossRef] [PubMed]

60. Pavlov, V.A.; Tracey, K.J. Neural regulation of immunity: Molecular mechanisms and clinical translation. Nat. Neurosci. 2017, 20, 156-166. [CrossRef] [PubMed]

61. Bonaz, B.; Sinniger, V.; Pellissier, S. Anti-inflammatory properties of the vagus nerve: Potential therapeutic implications of vagus nerve stimulation. J. Physiol. 2016, 594, 5781-5790. [CrossRef] [PubMed]

62. Koopman, F.A.; Chavan, S.S.; Miljko, S.; Grazio, S.; Sokolovic, S.; Schuurman, P.R.; Mehta, A.D.; Levine, Y.A.; Faltys, M.; Zitnik, R.; et al. Vagus nerve stimulation inhibits cytokine production and attenuates disease severity in rheumatoid arthritis. Proc. Natl. Acad. Sci. USA 2016, 113, 8284-8289. [CrossRef] [PubMed]

63. Pavlov, V.A.; Chavan, S.S.; Tracey, K.J. Molecular and Functional Neuroscience in Immunity. Annu. Rev. Immunol. 2018, 36, 783-812. [CrossRef]

64. Borovikova, L.V.; Ivanova, S.; Zhang, M.; Yang, H.; Botchkina, G.I.; Watkins, L.R.; Wang, H.; Abumrad, N.; Eaton, J.W.; Tracey, K.J. Vagus nerve stimulation attenuates the systemic inflammatory response to endotoxin. Nature 2000, 405, 458-462. [CrossRef] [PubMed]

65. Chavan, S.S.; Pavlov, V.A.; Tracey, K.J. Mechanisms and Therapeutic Relevance of Neuro-immune Communication. Immunity 2017, 46, 927-942. [CrossRef]

66. Zanos, T.P.; Silverman, H.A.; Levy, T.; Tsaava, T.; Battinelli, E.; Lorraine, P.W.; Ashe, J.M.; Chavan, S.S.; Tracey, K.J.; Bouton, C.E. Identification of cytokine-specific sensory neural signals by decoding murine vagus nerve activity. Proc. Natl. Acad. Sci. USA 2018, 115, E4843-E4852. [CrossRef] [PubMed] 